\title{
Utilizing Community-Based Social Marketing in a Recycling Intervention With Tailgaters
}

\author{
Nathan T. Martin \\ California State University, Northridge \\ Sally R. Ross \\ Grand Valley State University

\section{Richard L. Irwin} \\ University of Memphis
}

\begin{abstract}
The purpose of the current study was to design and implement a pilot intervention following the community-based social marketing (CBSM) process (McKenzieMohr \& Smith, 1999) and Darnton's (2008) social marketing framework to change the recycling knowledge and behaviors of tailgaters during home football events for a particular institution of higher education. Researchers asked what effect does a CBSM intervention have on the recycling behavior (via self-reported opinion and actual materials recycled) as well as self-reported knowledge among tailgaters during home football events for a particular IHE. In addition, researchers asked whether the use of students and student-athletes, from the respective IHE, as recycling educators would be better received by tailgaters than some other set of individuals. Both objective and subjective evidence support a conclusion that the pilot intervention enhanced the recycling behavior and recycling knowledge of tailgaters. Subjective evidence supports a conclusion that the tailgaters were more receptive to students and student-athletes than they would have been had some other set of individuals been the recycling educators. This study contributes to the body of knowledge by demonstrating that community-based social marketing approaches to behavior change, particularly multifaceted approaches incorporating a variety of techniques, are effective in positively changing behavior in a sport tailgating setting. Furthermore, this study provides insights for managers that tailgaters, in a context rife with identifiable constraints, are receptive to educational and behavior change-based interventions and participating in a research study
\end{abstract}

\footnotetext{
Martin is with Recreation and Tourism Management, California State University, Northridge, CA. Ross is with the Department of Movement Science, Grand Valley State University, Allendale, MI. Irwin is with the Department of Health and Sport Science, University of Memphis, Memphis, TN. Address author correspondence to Nathan Martin at nathan.martin@csun.edu.
} 
utilizing the methodologies outlined in the current study. The CBSM approach described herein may serve as an effective manner in which to approach these behavior-change initiatives, green or otherwise. The present study provides an example of how sport organizations, and college athletics in particular, can operate to address proenvironmental efforts specific to mitigating the burden that sport places on the physical environment.

Keywords: college sport, tailgating, recycling, community-based social marketing

The need to consider the natural environment in organizational management can be traced to numerous antecedents: from the simple increase in our collective awareness of human effects on the environment and resulting changes in personal value systems and expectations, to the more complex factors like strategic threats, governmental policy and intervention, and increasing globalization (Collins, Jones, \& Munday, 2009; Hart \& Milstein, 2003; Hillman \& Keim, 2001; Pfahl, 2010, 2011; Pfahl, Casper, Trendafilova, McCullough \& Nguyen, 2014; Ross, 2005; Shrivastava \& Scott, 1992; Smith \& Westerbeek, 2007; Thibault, 2009). Sport organizations are not immune to this need, and have recognized their own responsibility in this regard (Casper, Pfahl \& McSherry, 2012; Collins et al., 2009; Inoue \& Kent, 2012; Mallen, Adams, Stevens \& Thompson, 2010; Pfahl, 2011; Pfahl et al., 2014; Thibault, 2009). Furthermore, sport organizations are becoming more aware of their negative impact on the environment and the resulting scrutiny that accompanies such impact (Babiak \& Trendafilova, 2011; Casper et al., 2012; Hums, Barr, \& Guillon, 1999; Mallen $\&$ Chard, 2011). For instance, Collins et al. (2009) believed that measuring the environmental impact of sport events will become more salient as commitments to the environment are absorbed into organizational strategic plans and governmental objectives. As such, astute academic leaders in the sport management field have called for specific research examining the environmental impact of sport (Hums, 2010; Thibault, 2009; Zeigler, 2007).

The United Nations Environment Program (UNEP) (n.d.) stated, "whenever a person engages in sport there in an impact on the environment" (p. 1). Referring to negative impacts, these range from air pollution and waste generation to soil erosion and loss of biodiversity (Govender, Munien, Pretorious, \& Foggin, 2012; UNEP, n.d.). Sport fans are a part of this impact equation, as they often travel to and tailgate as a part of their experience, all while using resources such as fuel, electricity, and water to do so (Casper et al., 2014). Collins et al. (2009) found that top two factors that increased the ecological footprint of the 2004 Football Association (FA) Cup Final was visitor travel patterns and consumption of food and drink, respectively. They further estimated that the environmental footprint created by regular daily activity was seven times less than a trip to this FA event, specifically because participants engaged in a heightened state of consumption (Collins et al., 2009). Environmental impacts are not isolated to large or even mega-events in sport, as Trendafilova and Waller (2011) found ecological degradation concerns with the sport of disc golf.

Although sport often does have a negative impact on the environment, sport organizations can also be a mechanism for positive change (Kaufman \& Wolff, 2010). For example, Inoue and Kent (2012) described professional sport spectators as more likely to behave in proenvironmental ways if their team proactively 
promotes such behaviors. Babiak \& Trendafilova (2011) describe similar efforts across the professional sport realm including 'Green' games, purchasing carbon offsetting credits, and facility-wide recycling programs, noting that they are still an emerging phenomenon. Therefore, as these professional sport organizations continue to address the environment, other levels of sport organizations are likely to follow.

In the intercollegiate sport context, sport managers ought to address social concerns like environmental issues. However, until recently college athletics lagged conspicuously behind professional sport organizations when it came to promoting, practicing, and changing environmentally friendly behaviors. A survey of college athletic departments published by the Association for the Advancement of Sustainability in Higher Education found college athletic departments trailed professional sport teams in their commitment to sustainability and implementation of environmental initiatives (McSherry, 2009). This survey reported that sustainability was a "high" or "very high" priority for $72 \%$ of the universities as a whole, but only $44 \%$ reported it as an athletic department priority, and fewer than $10 \%$ of the athletic departments reported having a strategic plan for sustainability. While $80 \%$ of athletic departments had implemented "moderate" or "extensive" recycling initiatives, less than five percent were measuring recycling rates and setting goals for improving these rates across the entire athletic department. More recently authors and nongovernmental organizations suggested that institutions of higher education have a unique opportunity to affect change around environmental issues (Casper et al. (2014); National Resources Defense Council, 2013). In fact, National Governing Bodies (NGOs) like the Natural Resources Defense Council (NRDC) and the National Collegiate Athletic Association (NCAA) are affecting change across the intercollegiate sport landscape, recognizing best practices and setting high standards in the process (NRDC, 2012, 2013; NCAA, 2008). Given the popularity of college sport, athletes and fans can be effective advocates for social change initiatives (Casper et al., 2012). Casper et al. (2012) commented that because of their high-profile nature, student-athletes may be an untapped resource and will be asked to contribute to their department's environmental objectives. In addition, students or fans may be a unique choice to champion environmental issues, as McCullough (2013) identified how the influence of younger generations effectively encouraged older, nonstudent spectators to recycle during a large scale event, while also influencing their peers to do the same.

Therefore, the general purpose of the current study was to develop and test an intervention designed to reduce the environmental impact of tailgaters at a series of college football events, using college students as instruments to deliver the intervention. Community-based social marketing (McKenzie-Mohr \& Smith, 1999; McKenzie-Mohr, 2000) and a social marketing framework (Darnton, 2008) were used to inform the procedures for the intervention.

\section{Procedural Framework}

Significant predictors of proenvironmental behavior include opinions, information, behavioral skills, self-efficacy, attributions, and behavioral intentions (Bamberg \& Moser, 2007; Hines, Hungerford, \& Tomera, 1986). Regrettably, proenvironmental 
interventions continue to leverage mass media campaigns (e.g., advertising) as the sole tool to influence behavior change. In fact, while mass media may create awareness about proenvironmental behavior, these campaigns often have a nominal effect on actual behavior because awareness of a problem (such as environmental degradation due to lack of recycling) and the economic self-interest gains from behavior change may be insufficient to prompt meaningful behavioral changes (Andreasen, 1995; Geller, 1981; Geller, Erickson, \& Buttram, 1983; Johnston, 2006; Jordan, Hungerford, \& Tomera, 1986; McKenzie-Mohr \& Smith, 1999; Midden, Meter, Weenig, \& Ziverink, 1983; Tedeschi, Cann \& Siegfried, 1982). Social marketing, however, is a more effective technique that uses traditional marketing techniques to inform the public about issues, ultimately achieving socially desirable behavior change (Andreasen, 1994; Andreasen, 1995; Kotler \& Zaltman, 1971; Kotler, Roberto, \& Lee, 2002; Lefabvre \& Flora, 1988; McKenzie-Mohr, 2000).

\section{Social Marketing}

Kotler and Zaltman (1971) originally defined social marketing as "the design, implementation, and control of programs calculated to influence the acceptability of social ideas and involving considerations of product planning, pricing, communication, distribution, and marketing research" (p. 5). Kellison and Kim (2012) simplify the notion in the sport context as "any cause-based promotion intended to induce behavioral change among individuals" (p. 40). In the context of the current study, Brennan and Binney (2008) best define social marketing in that it "is used to prompt consumers to adopt environmentally friendly behaviors and lifestyles" (p. 42). One critique of past social marketing campaigns is that they sometimes lack consumer and market research before embarking upon an initiative (Wienreich, 1999). As such, sport managers wishing to effect change must first understand their target population before using a social marketing campaign.

The following studies help illustrate the social marketing concept in sport more specifically, and although they were conducted in the professional sport arena, similar needs exist in intercollegiate sport context as well (McSherry, 2009; NRDC, 2012, 2013; NCAA, 2008). Kellison and Kim's (2012) interviews with marketing executives supported professional sports teams' interest and effort in inspiring social change among their consumers through mass marketing tactics. However, they confirmed that further research is necessary to determine whether the teams' social marketing efforts are creating proenvironmental changes in consumers' actual behavior. In addition, Inoue and Kent (2012) attempted to determine if differences in newspaper reporting about a team's environmental practices would predict daily proenvironmental behavior. They found no significant correlation with their treatment and daily proenvironmental behavior, as well as a less than $10 \%$ prediction of their model on daily proenvironmental behavior. This suggests that other factors influence adoption of such behavior.

Some examples follow to further illustrate the state of proenvironmental movement in collegiate sport. Purdue University's Office of Sustainability and its Athletics Department, when in 2012 they began building a recycling program to increase recycling rates in the tailgating area by having student volunteers hand out recycling bags, $t$-shirts and using a communications and advertising package (Emrich, 2014). While commendable for encouraging the gathering of recyclables, 
these approaches did not seem to address identified barriers to recycling in a systematic, strategic way. Further, the coordinator of NCAA Men's basketball championships stated that after their sustainability efforts at the 2013 championships they look forward to expanding sustainable efforts to provide more education and engaging more fans in a sustainable lifestyle (NCAA, 2013). However, they simply deployed more than 200 recycling bins around the downtown area near the Georgia Dome to "encourage people to contribute to the cause" (NCAA, 2013).

\section{Community-based Social Marketing}

To address the needs that the above studies and articles identify, community-based social marketing (CBSM) expands on the use of mass media advertising alone to the strategic use of community-based direct contact initiatives (McKenzie-Mohr \& Smith, 1999; McKenzie-Mohr, 2000). Basically, CBSM has had more success because it connects knowledge with action (Kollmuss \& Agyeman, 2002). Therefore, the current study is procedurally grounded in CBSM (McKenzie-Mohr \& Smith, 1999; McKenzie-Mohr, 2000), as well as Darnton's (2008) "Nine Principles" social marketing framework. The first part of this section focuses on the CBSM process, with the second part briefly outlining Darnton's framework.

Community-based social marketing suggests that behavior-change interventions are most effective when implemented at a community level involving direct contact with representatives of the target audience (McKenzie-Mohr \& Smith, 1999; McKenzie-Mohr, 2000). Many projects and programs that attempt to positively change sustainable behavior leverage information (e.g., media advertising, distribution of printed materials), but they often fail because they overly rely upon knowledge/attitudes or economic self-interest; attempting to affect these antecedents to behavior often have little or no effect upon ultimate behavior (cf. McKenzie-Mohr, 2000).

While there is a paucity of formal academic research regarding CBSM and recycling in athletic venues, other results of successful CBSM exist showing how specific tools may be implemented to foster behavior change (see http://www. cbsm.com/public/world.lasso for a repository of peer-reviewed CBSM articles across disciplines). Generally, CBSM proceeds with "the careful selection of the behavior(s) to be promoted; identification of the barriers and benefits to the behavior, development of a strategy that addresses these barriers and benefits; pilot testing the strategy; and finally broad scale implementation" (McKenzie-Mohr, 2000, p. 543). Developed from the social psychology literature, CBSM utilizes behavior change tools including seeking commitments from participants; offering prompts as mental cues to encourage behavior change and the benefits of such change; developing and reinforcing norms; using captivating, credible and effective communication strategies; and using incentives that support the behavior change sought (McKenzie-Mohr \& Smith, 1999; McKenzie-Mohr, 2000). To further illustrate these behavior change tools, some example studies are outlined below.

Building of commitment has been used with positive results (see McKenzieMohr and Smith, 1999). Achieving the commitment of someone to an initially small request can build commitments to larger requests because individuals like to be perceived as behaving consistently (Cialdini, 1993; McKenzie-Mohr \& Smith, 1999). Those who agree to an initial request view themselves as a supporter; they 
then want to be perceived as consistent with that support in the future, even more so if the commitment is made publicly.

Since attention must be captured to initiate behavior change, the communication tool of CBSM must be vivid, personal, targeted, easy to remember, and presented by a credible source (McKenzie-Mohr \& Smith, 1999). Furthermore, modeling the preferred behavior is an additional method to effectively encourage behavior change, regardless of the method of communication (McKenzie-Mohr \& Smith, 1999; Winnett, et al., 1982; Winnett, Leckliter, Chinn, Stahl, \& Love, 1985).

Incentives are also a useful tool and are most effective where the incentive and the behavior are closely paired, where they are visible, and when they are more incentive than disincentive (Gardner \& Stern, 1996; McKenzie-Mohr \& Smith, 1999). Wang and Katzev (1990) described a recycling initiative that used incentives and commitment. In the successful intervention, four groups of residents were monitored: one group that signed a public commitment to recycle for four weeks, another group that made a private commitment, a third group that was offered incentives to recycle (coupons for local businesses), and a fourth control group that was given information leaflets. The first three groups demonstrated a significant increase in recycling when compared with the fourth (control) group.

Prompts can remind people to engage in activities that they might otherwise forget, but they must be noticeable, self-explanatory, and in close proximity to the site where the targeted behavior is to be carried out (McKenzie-Mohr \& Smith, 1999). Austin, Hatfield, Grindle and Bailey (1993) analyzed participation in a university campus recycling program, where one department had recycling signs detailing acceptable recyclable materials placed in immediate proximity to recycling and trash receptacles. Another department had the signs placed directly above the receptacles placed several meters apart. The proximity of the prompts proved to be important, as the first department's recycling activity increased by $54 \%$, and the second department's recycling activity was improved by only $17 \%$.

Behavioral change campaigns that use social norm tools help communicate that desirable behavior is happening more often than is believed (Schultz, Nolan, Cialdini, Goldstein, \& Griskevicius, 2007). In their study, Schultz et al. (2007) used social norms to encourage reduction in electricity consumption. In California, 290 households were provided with socially normative information about energy consumption in their neighborhood; their energy use was also monitored over four weeks. At the conclusion of each week, all households received door hangers displaying information about the energy the household had used in the previous week, normative information about the average energy consumption of houses in the neighborhood, and suggestions for reducing energy consumption (descriptive norms). Of the households that used less energy than the neighborhood average, half received normative support (e.g., a smiling face emoticon drawn on their door hangers indicating approval of usage) and the other half received simple descriptive norm information in the form of usage. Of those households that had higher than average energy use, half had a frowning face emoticon (indicating disapproval of usage) drawn on their door hangers and the other half received simple descriptive norm information in the form of usage. Those households that received the frowning face emoticon reduced their electricity use by six percent, compared with a reduction of $4.6 \%$ in those households that only received the descriptive norm 
information. For the households that had lower than average electricity use at the beginning of the campaign, those who received the smiling face increased their energy consumption by one percent, compared with a $10 \%$ increase observed in the group who did not receive this information.

The examples above illustrate the many and different behavior change tools that CBSM suggests employing to achieve the behavior change sought (McKenzie-Mohr \& Smith, 1999; McKenzie-Mohr, 2000). In combination, Darnton's (2008) framework integrates models of behavior with theories of change to best support the design and implementation of effective social marketing interventions. Since a brief review of the literature on social marketing has already been discussed, Darnton's (2008) "Nine Principles" social marketing framework is simply listed here and then contextualized later in the paper to frame the intervention:

1. Identify the audience groups and the target behavior.

2. Identify relevant behavioral models that help illustrate influencing factors.

3. Select the key influencing factors on which interventions might be focused.

4. Identify effective intervention techniques that have worked previously on the selected influencing factors.

5. Engage the target audience for the intervention to understand the target behavior and the factors influencing it from the target audience's perspective.

6. Develop a prototype intervention based on what was learned from the target audience.

7. Pilot the intervention.

8. Evaluate impacts and processes.

9. Transmit learning from the evaluation into the body of knowledge, future research, and future interventions.

Along with the call to examine environmental impacts and sustainability measures within the sport industry, the aforementioned CBSM process and the social marketing framework informed the purpose of the current study, its research questions, and methodology.

\section{Purpose of the Study and Research Questions}

The purpose of the current study was to design and implement a pilot intervention following the CBSM process and the social marketing framework to change the recycling knowledge and behaviors of tailgaters during home football events for a particular institution of higher education (IHE).

RQ 1: What effect does a CBSM intervention have on the recycling behavior (via self-reported opinion and actual materials recycled) among tailgaters during home football events for a particular IHE?

RQ 2: What effect does a CBSM intervention have on the self-reported knowledge among tailgaters during home football events for a particular IHE? 
RQ 3: Would the use of students and student-athletes from the respective IHE, as recycling educators, be better received by tailgaters than some other set of individuals?

\section{Methods}

The methods for the current study reflect an integration and adaptation of McKenzieMohr and Smith's (1999) process and Darnton's (2008) framework. An informed intervention that utilizes a model of behavioral change is appropriate in a college football-tailgating environment. This type of setting provides an opportunity to examine the opinions and behaviors of college athletics fans surrounding sustainability and recycling and to construct an informed strategy with numerous positive impacts.

\section{Setting}

The football team at a medium-sized, public, metropolitan, research institution of higher education (IHE) in the mid-South with NCAA Division I (Football Bowl Subdivision) affiliation played its home games at an off-campus, city-owned stadium managed by a professional facility management firm. In this setting, not only was there a failure to provide recycling opportunities for tailgaters in the facility's main parking areas, but there also were no recycling opportunities within the stadium itself. Furthermore, other spaces surrounding the stadium, including municipal parks and private parking lots, had no opportunities for on-site recycling. As the primary tenant of this facility, this IHE had no measure of a recycling program at its tailgating locations. The tailgating area was constrained by both geographic (e.g., restricted access points, fencing, and reserved parking spots) and demographic (e.g., football boosters) factors, and as such kept the tailgater population relatively consistent from event to event and season to season.

\section{Participants}

Participants for the current study were tailgaters in the aforementioned setting. The first set of participants was used as a formative group that established a baseline for recycling behavior and knowledge (Season1-Baseline group). The second set was used to determine the effect of the intervention, separated into those who participated in the intervention (Season2-Participant group) and those who did not (Season2-Nonparticipant group). While the tailgater population remained relatively consistent due to geographic and demographic constraints of the setting, researchers verified this assumption with chi-square tests for independence (with Yates Continuity Correction for $2 \times 2$ tables). These tests revealed that no differences existed across the demographics of sex, income, age, and education between the group that participated in the intervention (Season2-Participant group) and the group that did not (Season2-Nonparticipant group). Furthermore, the best way to determine if there is a difference between groups should directly relate to the dependent variable of interest more than simple demographics. As such, a one-way, between-groups analysis of variance (ANOVA) was conducted to explore the differences in selfreported recycling behavior at home between the Season2-Participant group and 


\section{Table 1 Differences Between Intervention Groups} (Chi-square and ANOVA)

\begin{tabular}{ll}
\hline Sex & $\chi_{\text {(sex) }}^{2}(1, n=348)=1.572, p=.21$ \\
Income & $\chi_{\text {(income) }}^{2}(5, n=312)=1.267, p=.939$ \\
Age & $\chi_{\text {(age) }}^{2}(5, n=341)=.976, p=.964$ \\
Education & $\chi_{\text {(education) }}^{2}(4, n=343)=5.237, p=.264$ \\
Recycling Behavior While at Home & $F(1,340)=.081, p=.776$ \\
\hline
\end{tabular}

Season2-Nonparticipant group. No difference was found across groups on selfreported recycling behavior at home. For further description of these participants, please see Table 1 .

\section{Instrument}

Recognizing that a lengthy questionnaire may severely limit response rate in a tailgate environment, researchers developed and refined a questionnaire item list that best reflected a broad survey of the literature, and then identified and modified items most salient for use in a tailgate-specific questionnaire. These respective questionnaire items were taken from a variety of recycling resources reviewed by the research team (Aceti Associates, 2002a; Aceti Associates, 2002b; Aceti Associates, 2002c; Barker, Fong, Grossman, Quin, \& Reid, 1994; Barr, Gilg, \& Shaw, 2005; Boerschig \& De Young, 1993; De Young, 1989a; De Young, 1989b; Galbraith \& McNabb, 1998 as cited in Galbraith \& McNabb, 1999; Hopper \& Nielsen, 1991; Research International, 2000). Once created, the questionnaire was pilot tested with two different groups of students in a research course to determine issues with readability, understanding, and validity based on content, as well as the amount of time required to complete the questionnaire. While additional items on the instrument were used for other purposes, the current study's purposes used three specific sections of the instrument that are further described below.

First, as suggested by Darnton (2008) and McKenzie-Mohr and Smith (1999), items were used to explore and confirm influencing factors on recycling as well as to help direct researchers to areas where interventions should be focused. As such, items regarding constructs including knowledge ("I am knowledgeable about recycling; My knowledge of recycling drives me to recycle"), social norms ("I spend my time with people who recycle; Seeing other people recycling drives me to recycle"), and perceived effort ("Recycling takes little effort; The ease of recycling drives me to recycle") were included that used a 6-point Likert scale ranging from one (strongly disagree) to six (strongly agree). The data from these items were only used to inform the intervention for the purposes of the current study.

Second, researchers measured respondents' self-reported opinions about their recycling behavior at home and while tailgating utilizing a 6-point Likert scale ranging from one (almost never) to six (almost always). Specifically, the two items were phrased as "At home, I recycle all that is recyclable" and "While tailgating, I recycle all that is recyclable." 
Third, since no current scales existed that could elicit opinions about recycling educators, researchers created six items to determine tailgaters' opinions of the IHE's students and student-athletes as recycling educators. These items had initial evidence of validity based on content analysis through a pilot study and supportive evidence of validity based on internal structure of the items. These items used a 6-point Likert scale ranging from one (strongly disagree) to six (strongly agree), with the items including "I would respond more positively to being approached by someone other than University students and student-athletes" and "I would actually recycle more often after hearing a tailgate-recycling message from someone other than University students and student-athletes."

\section{Baseline Procedures}

To identify the baseline self-reported opinions about recycling behavior of the tailgaters, researchers surveyed a large convenience-based sample of the tailgater population $(n=407)$ using a direct intercept via questionnaire approach; this created the Season1-Baseline group data set. This exploration confirmed the fact that respondents in the Season1-Baseline group, when in this tailgate setting void of any venue- or event-orchestrated recycling opportunities, did recycle less than they did at home (see the Data-driven Intervention subsection in the Results section).

\section{Intervention Procedures}

After collecting initial data, the researchers also conducted a simple regression analysis to help direct researchers to areas where interventions should be focused, per Darnton's (2008) steps two and three and McKenzie-Mohr and Smith (1999). As such, $51 \%(F(5,392)=27.04, p<.001)$ of the variance in the 'recycling while tailgating' scores was predicted by a simple multiple regression model. In the model, only the knowledge component (beta $=.24, p<.001$ ) was a statistically significant factor that was actionable from an intervention perspective, so it was included as part of the planned CBSM intervention.

Next, the researchers relied on McKenzie-Mohr and Smith's (1999) suggestions to accomplish Darnton's (2008) fourth step. Specifically, these suggestions include the techniques of encouraging commitment and consistency, providing cues, prompts, and incentives, promoting social norms, and removing external barriers. The data captured from the questionnaire on the opinions of tailgaters also addressed step five of Darnton's framework, where researchers used the collected information to gain an understanding of the factors affecting recycling behavior. The remaining part of this section details step six of Darnton's framework as the most important part of the methodology: the development of a prototype intervention based on the knowledge acquired from the target audience.

Researchers worked in conjunction with students from the IHE's chapter of the Sport Marketing Association, Department of Athletics Student Athlete Advisory Committee and CHAMPS/Life Skills program, Sport Management academic program, and Environmental Action Club to implement an intervention focused on the knowledge and behavior of tailgaters. The students and student-athletes from the aforementioned organizations were recruited to serve as recycling educators. This group of educators specifically addressed McKenzie-Mohr and Smith's (1999) 
assertion that behavior-change interventions are most effective when implemented at a community level involving direct contact with representatives of the target audience. Since members of the tailgating population were alumni and supporters of the IHE and its athletic teams, using students and student-athletes not only provided a unique community-engagement opportunity, it also addressed calls for such use in the sport literature (Casper et al., 2012; McCullough, 2013).

Initially, a series of workshops was conducted to educate student and studentathlete volunteers about recycling, particularly in a setting that features tailgating. They were trained to effectively engage event tailgaters via a personal intercept method, as well as to understand the logistical requirements for leveraging additional intervention techniques suggested by McKenzie-Mohr and Smith (1999). The workshop training sessions were designed by one of the faculty researchers who had expertise and consulting experience with such environments and personal intercept methods. As such, multiple roles were created so that each volunteer could self-select one that best met individual strengths or most mitigated individual concerns. Specific instructions and scripts for each role were developed reflecting objectives for the personal intercept. They are described briefly in the Appendix.

These roles were practiced (i.e., role played) during the workshop sessions, helping clarify expectations and identify potential responses and pitfalls that could occur in the tailgate setting. Reflective of Darnton's (2008) seventh step, students then applied their training in an intervention with participants in a tailgating environment with supervision and guidance from the research team. Each team was assigned a section (row of tailgating spots) where they were instructed to select approximately $33 \%$ of the participants in their respective section at random. Random was defined loosely with these teams so their focus would remain on the intervention tactics and not the research methodology.

One intervention strategy, as identified by the exploratory research, was focused on the knowledge of the tailgaters. Adorned in IHE approved athletics logo t-shirts with "We Can Talk Trash" printed on the front and impactful statements about recycling printed on the back, student educators approached groups of tailgaters and initiated casual conversations about the IHE's football team. Next, the trained educators followed predetermined scripts to encourage discussions about recycling. Using the back of the t-shirts as talking points, five groups of six student educators focused on tailgaters' recycling knowledge, providing details about recycling while tailgating and strategies tailgaters can use to recycle more.

Another intervention technique was implemented to leverage people's desire to remain consistent with any commitment they publically assert (Cialdini, 1993). As the educators concluded their efforts to increase individuals' knowledge about tailgating, they asked tailgaters if they would be willing to commit to recycling while tailgating and to additional sustainable behaviors. The pressure of their peer group helped generate affirmative responses to this request and to further enhance the commitment, any affirmative response was followed up with a public and group commitment request (Pallak, Cook \& Sullivan, 1980; Wang \& Katzev, 1990). Specifically, the tailgater was asked to sign a document indicating a promise to (a) place aluminum cans, plastic bottles and glass bottles in on-site recycling bins; (b) buy and use more products in containers that can be recycled; (c) encourage those with whom I tailgate to recycle more. These two components 
of the commitment-consistency technique were well suited to pair with the third additional technique for the intervention, incentives.

To enhance the commitment-consistency technique and consequently recycling behavior, incentives for the aforementioned behaviors were provided. First, in return for signing the commitment document publicly, each individual was offered a sticker bearing the IHE athletics logo that stated, "I recycle when I tailgate." Tailgaters were encouraged to put these stickers on items in their tailgate area, including their motor and recreational vehicles, coolers, and trash containers. In addition, the opportunity to include an e-mail address on the commitment card entered the participant into a drawing for an IHE-approved athletics logo t-shirt.

The aforementioned stickers and t-shirts also served as an intervention technique. These items served as visible reminders to recycle. Furthermore, real or imagined social pressure can encourage people to change behaviors or opinions in an attempt to conform (Aronson, 1999). Displaying giveaway items can help identify those who recycle, and in situations where people want to gain and maintain acceptance within a group (or to avoid becoming an outcast), these items are particularly salient. Indeed, wearing prorecycling t-shirts and displaying "I recycle" stickers signifies the extent to which recycling is valued. In addition, stickers were strategically placed on public trashcans, portable outdoor public restrooms, light poles, and other relatively stationary items to enhance exposure and response to the cues and prompts.

Since no on-site recycling opportunities for tailgaters were initially available, a structural barrier to recycling existed. As such, a local Coca-Cola bottling company agreed to sponsor the intervention and provide containers in the tailgating area. The recycling containers were strategically placed in easily accessible locations directly next to trash containers, as research suggests that placing recycling containers proximal to trash containers encourages recycling (Austin, Hatfield, Grindle, \& Bailey, 1993; Ludwig, Gray, \& Rowell, 1998). Furthermore, the recycling bins were placed in the tailgating environment during two home events preceding the first collection of recyclable materials. This was an additional mechanism to better isolate the intervention and control for its effects.

\section{Recycling Behavior and Attitude Measurement Procedures}

To determine the number of users at the tailgating site, head counts were conducted at two different times: one hour before kickoff and 30 minutes before kickoff. These counts were conducted independently by at least three individuals and then averaged across the number of individuals and the two times for an overall head count.

To accurately measure the amount of recyclable materials over time, recycling bins were made available in the tailgate environment four hours before event start time and remained until one hour after the event ended. At the conclusion of each event, all materials collected in the recycling bins were sorted from contaminants and transported to a local recycling center for weighing and processing.

The same process used to collect initial data for the intervention (Season1Baseline group data) was also used to collect self-reported recycling data at the final event of the season (both Season2-Participant and Season2-Nonparticipant group data). This data collection also coincided with the final day of recycling 
material collection (Event 3). Please see the Baseline Procedures subsection of the Methods section for a description of that general process. The Season2-Participant and Season2-Nonparticipant groups were different than the Season1-Baseline group in that they were surveyed in different seasons and for different reasons (Formative versus Intervention/Control effects). The difference between the Season2-Participant and Season2-Nonparticipant groups was that the Season2Participant participated in the direct-contact intervention, while the Season2Nonparticipant did not. They were asked exactly the same questions except for one demographic question, in which their response to whether they participated in the direct-contact intervention classified them as either Season2-Participant or Season2-Nonparticipant.

\section{Controls}

To improve the design, numerous controls were instituted. One was the tailgate setting selected. Because it was constrained by both geographic (e.g., restricted access points, fencing, and reserved parking spots) and demographic (e.g., football boosters) factors, it kept the tailgater population relatively consistent from event to event and season to season. In addition, since members of the population were in predictable locations from event to event and season to season, particular controls regarding bin exposure were more effective because environmental conditioning of tailgaters occurred. Another control was the achieved sample size. Since researchers wanted a sample size that would be at a $95 \%$ confidence level with a $5 \%$ margin of error, at least 277 tailgaters needed to be sampled of the 985 in the population that day. Since 392 tailgaters were actually sampled, the sample size was more than adequate and helped to offset the lack of true random selection. Another control to further improve design was to match the comparison group characteristics that relate to the dependent variable. In this study comparison groups were analyzed for differences in demographics and recycling behavior at home and found no significant differences across all five, thus making them comparable. Other controls included (a) constraining the duration of recycling container access during each event to control for amount of time tailgaters could place items into a container; (b) off-site independent weighing of collected recyclable materials; (c) placing recycling containers during two preceding events to condition tailgaters to such an environment before the baseline measure and direct contact of the intervention; (d) statistical analysis controls for confounding variables like group similarities and bin exposure.

\section{Results}

\section{Data-driven Intervention}

Survey data were collected from tailgaters at two different home football events and analyzed before creating intervention strategies. Among other analyses less salient for reporting here, researchers conducted a paired-sample $t$ test to determine differences in recycling behavior at home versus while tailgating. On a Likert scale of one (almost never) to six (almost always), results indicated that there was a significant difference between respondent recycling behavior while at home 
$(M=3.7, S D=1.76)$ compared with while tailgating $(M=2.36, S D=1.69), t(407)$ $=13.89, p<.001, \eta^{2}=.32$. This fact confirmed that the tailgating environment was ripe for an intervention regarding recycling.

\section{Recycling Behavior Change}

Attendance at the home football events were drawn from figures reported to the National Collegiate Athletic Association. To confirm the accuracy of the head count conducted at each tailgate event, it was correlated with the reported event attendance using Pearson product-moment correlation. The head counts were consistent with attendance $(r=.978, p=.022)$. The baseline recyclable material collection was established at .13 pounds per person and the final collection yielded .45 pounds per person. For a complete presentation of the results of the recyclable materials collected, please see Table 2.

A one-way, between-groups analysis of variance (ANOVA) was conducted to explore the differences in self-reported recycling behavior between those who participated in the intervention (Season2-Participant group) and those who did not (Season2-Nonparticipant group). The analysis indicated that there was a statistically significant difference, $F(1,332)=20.045, p<.001$, where the mean score on self-reported recycling behavior for the Season2-Participant group $(M=4.04$, $S D=1.75$ ) was greater than the mean score for the Season2-Nonparticipant group $(M=3.17, S D=1.77)$. According to Cohen (1998), the eta-squared statistic (.06) indicated a medium effect size.

The same analysis was conducted to explore the differences in self-reported recycling behavior between the Season2-Nonparticipant group and the Season1Baseline group. It indicated that there was a statistically significant difference, $F(1$, $597)=28.94, p<.001$, where the mean score for the Season2-Nonparticipant group $(M=3.17, S D=1.77)$ was greater than the mean score for the Season1-Baseline group $(M=2.36, S D=1.69)$. The eta-squared statistic $(.05)$ indicated a small effect size (Cohen, 1988).

The same analysis was conducted to explore the differences in self-reported recycling behavior between the Season2-Participant group and the Season1-Baseline group. It indicated that there was a statistically significant difference, $F(1,544)=$ $102.17, p<.001$, where the mean score for the Season2-Participant group $(M=$ $4.06, S D=1.73$ ) was significantly greater than the mean score for the Season 1 Baseline group $(M=2.36, S D=1.69)$. The eta-squared statistic (.16) indicated a large effect size (Cohen, 1988).

\section{Table 2 Recycling Material Weights by Intervention Time (head count of tailgaters)}

\begin{tabular}{ll}
\hline Season2-Preintervention & \\
Baseline Event (Attendance: 20,063$)$ & .13 pounds per person $(n=1060)$ \\
Season2-Postintervention & \\
Event 1 (Attendance: 18,284$)$ & .24 pounds per person $(n=850)$ \\
Event 2 (Attendance: 18,031$)$ & .45 pounds per person $(n=985)$ \\
\hline
\end{tabular}


The simple exposure to recycling bins that previously were not available may have had an effect on the self-reported recycling behavior of respondents. As such, hierarchical multiple regression was used to control for this confounding variable. Preliminary analyses were conducted to ensure no violation of the assumptions of normality, linearity, multicollinearity, or homoscedasticity. Frequency of bin exposure was entered at Step 1, explaining $0.5 \%$ of the variance in self-reported recycling behavior. After entering the variable of whether one was visited by a member of the intervention team at Step 2, the total variance explained by the model as a whole was $5.7 \%, F(2,331)=10.067, p<.001$. Therefore, being visited by a member of the intervention team explained significantly more (an additional $5.2 \%$ ) of the variance in the self-reported recycling behavior than did bin exposure, $R_{\text {change }}^{2}=.052, F_{\text {change }}(1,332)=18.237, p<.001$.

While not a focused component of the current study, a noteworthy result was found. Across groups (Season1-Formative, Season2-Participant, Season2Nonparticipant), no significant differences were found in self-reported recycling behavior while at home; all differences found were only in self-reported recycling behavior while tailgating.

\section{Recycling Knowledge Change}

A one-way, between-groups ANOVA was conducted to explore the differences in self-reported recycling knowledge between the Season2-Participant group and the Season2-Nonparticipant group. It indicated that there was a statistically significant difference, $F(1,339)=8.69, p<.001$, where the mean score for the Season2Participant group $(M=5.16, S D=0.96)$ was greater than the mean score for the Season2-Nonparticipant group $(M=4.80, S D=1.20)$. According to Cohen (1998), the eta-squared statistic (.03) indicated a small effect size.

\section{Reception of Students and Student-athletes}

To determine tailgater opinion about the use of students and student-athletes as recycling educators versus a different set of individuals, six items reflecting such a construct were collapsed into one scale. The internal consistency of the scores produced by this scale was determined using Cronbach's alpha, resulting in a high level (.89) of reliability and supporting evidence of validity based on internal structure (AERA/APA/NCME, 1999). Descriptive statistics were calculated to explore tailgaters' opinions about the use of students and student-athletes as recycling educators as opposed to the use of another group. All respondents $(n=344)$ were included in the analysis and a mean score of less than 3.5 (midpoint of the 6-point Likert scale) would reflect a positive reception of students and student-athletes as recycling educators rather than a different set of individuals. A range of 1-4.5 and a mean score of $2.06(S D=1.02)$ was found.

\section{Discussion}

The present study contributes to the increasing efforts to foster the behavior often referred to as "going green" in the college sport context. Specifically, it provides insights into recycling in a college-tailgating environment utilizing two procedures 
or frameworks of behavior change. Community-based social marketing has much to offer in enhancing sustainable behavior. This section discusses the evidence provided by the current study's intervention specific to the study's research questions, the implications of such evidence, as well as the main limitations of the study.

\section{Research Questions}

Research question one sought to discover the effect of a CBSM intervention on recycling behavior (via self-reported opinion and actual materials recycled) among tailgaters during home football events for a particular IHE. Both the objective and subjective evidence support a conclusion that the intervention enhanced the recycling behavior of tailgaters. More specifically, the objective evidence of the amount of recyclable materials collected grew from .13 to .25 to .45 pounds per person. While the increase in the amount of recycled materials supports a conclusion that the intervention enhanced the recycling behavior of tailgaters, other evidence was needed to bolster this claim. As such, a subjective measure of recycling behavior was assessed using a postintervention questionnaire. A one-way, betweengroups ANOVA procedures identified that the Season2-Participant group had significantly greater self-reported scores for recycling while tailgating than the Season2-Nonparticipant group and the Season1-Baseline group. In addition, the analysis identified that the Season2-Nonparticipant group had significantly greater self-reported scores for recycling while tailgating than did the Season1-Baseline group.

While all the analyses reported herein were found to be statistically significant, the same results may not be practically significant. Therefore, a better indicator of the intervention's practical outcome is its effect size. A large effect size (Cohen, 1988) was reported for the Season2-Participant group compared with the Season1-Formative, yet only a medium effect size was reported for the Season2Participant group compared with the Season2-Nonparticipant group. While the large effect size between the Season2-Participant group and both the Season2Nonparticipant group and the Season1-Baseline group fit the likely outcomes asserted by McKenzie-Mohr and Smith (1999), the medium effect size between the Season2-Nonparticipant group and the Season1-Baseline group is perplexing because there should be a small effect, if any. However, the observed difference is explainable if the elements of CBSM do what they are intended to do. Indeed, the techniques suggested by McKenzie-Mohr and Smith (1999) are not only supposed to directly affect intervention participants, but they should also indirectly affect other community members. Specifically, the techniques of enhancing knowledge about recycling, using cues and prompts, and leveraging social norms may have provided these indirect effects, helping to explain the aforementioned result. Based on this evidence, it appears that the intervention enhanced the recycling behavior of tailgaters.

While removing external barriers to recycling (i.e., providing recycling bins that were not previously on site) was a component of the intervention, the simple exposure to recycling bins may have been the sole contributor to the increase in the self-reported recycling behavior of respondents. While much observational and photographic evidence was collected that showed how tailgaters failed to recycle 
even when recycling bins were made available during the two preceding events (e.g., many tailgaters discarded recyclable materials into a trash container that was directly adjacent to a recycling bin), this evidence is solely anecdotal. Therefore, hierarchical multiple regression was used to control for this theoretically confounding variable. Only $0.5 \%$ of the variance in self-reported recycling behavior while tailgating was explained by bin exposure, and after controlling for this effect, the Season2-Participant group still had significantly greater self-reported recycling behavior while tailgating. These facts suggest that bin exposure had a negligible effect on recycling behavior while tailgating, providing additional evidence that the other components of the intervention were important.

The effect of the increased recycling behavior may have been less a result of the actual intervention and more a result of an overall increase in public awareness and concern regarding environmental issues. Therefore, nonintervention related influences might have been entirely responsible for the change in recycling behavior in the current study, so identifying discriminating evidence that helps confirm or refute that fact is warranted. One such piece of evidence was conducted by the Pew Research Center (2009). Perceptions about global warming serve as one of many proxies for proenvironmental behavior like recycling. From an historical perspective, the American perception toward global warming remained steady from 2006-2008 (Pew, 2009), and one would expect that it would remain steady in 2009 and perhaps increase due to the cultural evolution toward "going green" that has occurred across the United States. Yet, a poll conducted by the Pew Research Center between September 30 and October 4, 2009 (coincidentally this poll was conducted at the same time as the present intervention) reported a $14 \%$ decline in the American perception about global warming (2009).

Additional discriminating evidence from a local perspective also supports the intervention's effectiveness. According to the Bureau of Solid Waste Management, the annual recycling tonnage within the Metropolitan Statistical Area where the stadium exists, dropped consistently from 9,774 tons (2008) to 9,600 tons (2009) to 8,992 tons $(2010)$, while the population remained stable during that same period of time (676,660 in 2008; 676,640 in 2009) (U.S. Census Bureau, 2011). Furthermore, since there was no difference found across groups on self-reported recycling behavior while at home even though there was a large difference found across groups while tailgating, the evidence suggests that the intervention actually changed behavior in the localized tailgating context.

The second research question sought to discover the effect of a CBSM intervention on the self-reported knowledge among tailgaters during home football events for a particular IHE. The subjective evidence supports a conclusion that the intervention enhanced the recycling knowledge of tailgaters. One-way between-groups ANOVA procedures identified that the Season2-Participant group reported having significantly greater recycling knowledge than the Season2-Nonparticipant group. While the analysis reported herein was found to be statistically significant, only a small effect size (Cohen, 1988) was noted. Such a small effect size may indicate that the knowledge component of the intervention was not as robust as it could have been. Ackerman, Beier and Bowen (2002) however, explain that self-reported subjective assessments about a common topic generally reflect an overestimation of the respondent's actual knowledge. Therefore, if any effect was found, it would 
likely be small due to the original overestimation about respondents' own recycling knowledge. Furthermore, as McKenzie-Mohr and Smith (1999) stated, enhancing knowledge should be used in conjunction with other techniques to enhance behavior, as awareness, knowledge, and action are very different things (Casper et al., 2012; Casper et al., 2014).

The third research question for the current study asked if the use of students and student-athletes from the respective IHE, as recycling educators, would be better received by tailgaters than some other set of individuals. The subjective evidence supports a conclusion that the tailgaters were more receptive to students and student-athletes than they would have been had some other set of individuals been the recycling educators. While the term "some other set" was not defined, it seems that on average tailgaters thought that students and student-athletes were a good choice in relation to their self-conceived alternatives.

\section{Implications}

The present study contributes to the body of knowledge by demonstrating that community-based social marketing approaches to behavior change, particularly multifaceted approaches incorporating a variety of techniques as suggested by McKenzie-Mohr and Smith (1999) and Darnton (2008), are effective in positively changing behavior in a sport context, as called for in the recent literature (Mallen et al., 2011). Since collegiate athletic departments are beginning to bridge the gap between themselves and their professional sport counterparts in their commitment to sustainability and implementation of environmental initiatives (McSherry, 2009; NRDC, 2012, 2013; NCAA, 2008), the current study provides a strategic framework and tactical template for effective sustainability initiatives that resonate with key college athletics stakeholders. While lack of environmental efforts in collegiate sport may no longer be the norm moving into the future, there are settings that still exist that are ripe for improvement, and advancement of action-oriented, directcontact initiatives that result in actual behavior change are underutilized according to the literature; the current study advances such a perspective on both fronts. As suggested, proenvironmental initiatives have numerous positive outcomes affecting the triple bottom line of environmental, social, and economic benefits (Elkington, 1998; Kellison \& Kim, 2012).

In addition, the current study adds insight regarding the limitations of these approaches. More specifically, this study demonstrates that while these approaches are effective at positively changing behavior, the change is very context specific. Indeed, consistent with other sport studies (McCullough, 2013; McCullough \& Cunningham, 2012) an increase in recycling behavior does not transfer across settings; individuals reported no increase in recycling when they are at their homes. This fact gives further credence to the specific tactics used in the current study's intervention, such as cues and prompts, social norming, and removal of barriers that could not be implemented and leveraged at participants' homes. Since this is a consistent finding among sport settings, it begs the question of how sport organizations can transcend the sport environment with their initiatives to affect a larger scope of proenvironmental behavior.

Casper and colleagues $(2012 ; 2014)$ support this finding and report the need to better understand fans' awareness, knowledge, and actions and the linkage to 
their everyday lives. While CBSM interventions may continue to change behavior in localized contexts, this value-gap (Blake, 1999; McCullough \& Cunningham, 2012) may be better addressed by emphasizing the social components of the triple bottom line (Elkington, 1998; Kellison \& Kim, 2012). Relatedly, perhaps the psychosocial tactics recommended by McKenzie-Mohr \& Smith (1999) could be applied to home and work settings. Examples may include teams offering earned incentives such as (a) meet and greets with players and coaches with proof of proenvironmental behavior while at home or work; (b) team branded cues/prompts could be distributed for placement in conspicuous places at home like a front yard or mailbox; (c) neighborhood or workplace "commitment drives" could be facilitated or spearheaded by teams, players, or coaches. This question of how sport organizations can transcend the sport environment with their initiatives to affect a larger scope will continue to confront sport's potential effect on proenvironmental behavior.

In addition, the current study provides insights for managers that tailgaters, in a context rife with identifiable constraints, are receptive to educational and behavior change-based interventions and participating in a research study utilizing the methodologies outlined in this study. This fact informs managers that there exists a relatively untapped 'captive audience' in which to engage for numerous community-based social marketing initiatives, green or otherwise, that add action and tangible results to the messaging tactics so often used (McKenzie-Mohr, 2000). As previously discussed, sport managers are attempting to be green in many ways, including developing and implementing initiatives to increase recycling. The present study demonstrates that action-based approaches are very effective in providing managers with measureable evidence to prove that they are authentically green. This will not only protect against greenwashing (Delmas \& Burbano, 2011), diminishing returns on investment (Walker \& Kent, 2009), and consumer backlash (Drumwright, 1996; Osterhus, 1997), but because of this measureable evidence of action and not just knowledge or intention to act, sport managers are much better positioned to leverage their authentic green endeavors for other acquirable resources and positive outcomes.

Finally, the current study provides evidence that the use of students and studentathletes as the direct-contacts for a CBSM intervention in a tailgating context was an effective choice, supporting other invitations for such a consideration (Casper et al., 2012; McCullough, 2013). This evidence also supports the CBSM component that calls for community interaction involving direct contact with representatives of the target audience (McKenzie-Mohr \& Smith, 1999). Therefore, the specification of college students and college student-athletes as the members who provide direct community interaction in college sport settings may enhance the effectiveness of community-based social marketing initiatives.

\section{Limitations}

Community-based action research, by design, is not experimental. As such, one should be concerned about internal validity and the causal inferences made from such research. The present study does allow for more confidence in the effect of the intervention than if the methods were simply the collection of cross-sectional data or if interviews or questionnaire-only methods were conducted with tailgaters. Not 
only was random selection and assignment not feasible in such a control-challenged research environment, additional threats to internal validity like unknown nonintervention related influences and time-elapsed effects could be present. While efforts were made to design the present investigation to control for the intervention as much as possible in community-based action research setting, threats to internal validity are a limitation of the current study.

While the current study did find differences in self-reported recycling behavior between home and tailgating settings, suggesting respondents answered honestly and accurately, a limitation of all self-reported research that investigates social behavior may suffer from social desirability bias. Therefore, the self-reported scores on items such as recycling behavior may be inflated to reflect a more positive self-view of the respondents.

No prior research examining community-based social marketing existed to confirm the effectiveness of the process suggested by McKenzie Mohr and Smith (1999) or Darnton's (2008) framework in a tailgating environment. Being that this was an inaugural context for this process/framework, additional research needs to be conducted to determine whether and to what extent the current study's unique setting (i.e., being an off-campus facility, managed by a non-university-based company, with the absence of any recycling opportunity) may have facilitated the effect of the intervention more so than had the setting been more traditional (i.e., on-campus facility managed by a university entity with a recycling program). Relatedly, limitations around external validity also exist due to the nature of the sample/population and the setting.

Finally, individual components of the intervention were not isolated for measure of effect, only the intervention in its entirety. As such, further research that isolates single components of the intervention, perhaps in quasi-control groups, needs to be conducted to determine the most effective components of the intervention so that practitioners in sport environments can best deploy and manage their scarce resources.

\section{Conclusion}

A proenvironmental initiative undertaken by college athletic departments may positively impact the environment. However, in utilizing these initiatives, college athletic departments must continue to evolve and refine their efforts. This evolution will require these organizations to affect change beyond the walls of the parent institution, like in tailgating environments outside their sport facilities where they have less control, and even larger-in-scope possibilities like in their fans' home and work environments. The CBSM approach described herein may serve as an effective manner in which to approach these behavior-change initiatives, green or otherwise, so college athletic departments can best meet the call of late NCAA President Myles Brand (2005): "We should not underestimate the potential of athletics to contribute to social change, nor should we shy away from that responsibility." The present study, using a game-day recycling initiative as context, provides an example of how sport organizations, and college athletics in particular, can operate to address proenvironmental efforts specific to mitigating the burden that sport places on the physical environment. 


\section{References}

Aceti Associates. (2002a). A community-based social marketing tool for increasing participation in recycling and waste reduction: Model bid specification for phone survey research. Boston, MA: Massachusetts Department of Environmental Protection.

Aceti Associates. (2002b). Recycling: Why people participate; why they don't. Boston, MA: Massachusetts Department of Environmental Protection.

Aceti Associates. (2002c). Multifamily recycling: Barriers and opportunities. Boston, MA: Massachusetts Department of Environmental Protection.

Ackerman, P.L., Beier, M.E., \& Bowen, K.R. (2002). What we really know about our abilities and our knowledge. Personality and Individual Differences, 33, 587-605. doi:10.1016/ S0191-8869(01)00174-X

American Educational Research Association. American Psychological Association, National Council on Measurement in Education [AERA/APA/NCME]. (1999). Standards for educational and psychological testing. Washington, DC: American Psychological Association.

Andreasen, A.R. (1994). Social marketing: Its definition and domain. Journal of Public Policy \& Marketing, 13, 108-114.

Andreasen, A.R. (1995). Marketing Social Change: Changing Behavior to Promote Health, Social Development and the Environment. San Francisco, CA: Jossey Bass.

Aronson, E. (1999). The Social Animal. New York, NY: Worth Publishers.

Austin, J., Hatfield, D.B., Grindle, A.C., \& Bailey, J.S. (1993). Increasing recycling in office environments: The effects of specific, informative cues. Journal of Applied Behavior Analysis, 26, 247-253. PubMed doi:10.1901/jaba.1993.26-247

Babiak, K., \& Trendafilova, S. (2011). CSR and environmental responsibility: motives and pressures to adopt green management practices. Corporate Social Responsibility and Environmental Management, 18(1), 11-24. doi:10.1002/csr.229

Bamberg, S., \& Moser, G. (2007). Twenty years after Hines, Hungerford, and Tomera: a new meta-analysis of psycho-social determinants of pro-environmental behavior. Journal of Environmental Psychology, 27, 14-25. doi:10.1016/j.jenvp.2006.12.002

Barker, K., Fong, L., Grossman, S., Quin, C., \& Reid, R. (1994). Comparison of self-reported recycling attitudes and behaviors with actual behavior. Psychological Reports, 75(1), 571-577. doi:10.2466/pr0.1994.75.1.571

Barr, S., Gilg, A., \& Shaw, G. (2005). Promoting sustainable lifestyles: A social marketing approach (Technical Report). Exeter, Devon: University of Exeter.

Blake, J. (1999). Overcoming the 'value-action gap' in environmental policy: Tensions between national policy and local experience. Local Environment: The International Journal of Justice \& Sustainability, 4, 257-289.

Boerschig, S., \& De Young, R. (1993). Evaluation of selected recycling curricula: Educating the green citizen. The Journal of Environmental Education, 24(3), 17-22. doi:10.108 0/00958964.1993.9943498

Brand, M. (2005, October 24). NCAA correctly positioned as a catalyst for social change. The NCAA News President's Forum. Retrieved from http://www.ncaa.org/wps/ ncaa?ContentID $=1190$

Brennan, L., \& Binney, W. (2008). Concepts in conflict: Social marketing and sustainability. Journal of Nonprofit \& Public Sector Marketing, 20, 261-281. doi:10.1080/10495140802224951

Bureau of Solid Waste Management. City of [Removed]. (2008). Disposal/Diversion/Revenue/Savings Master Summary. Retrieved from http://www.cityof[Removed].org/pdf_ forms/Disposal-Diversion-Revenue-Savings\%20_MasterSummary_CalendarYr08.pdf

Bureau of Solid Waste Management. City of [Removed]. (2009). Disposal/Diversion/ Revenue/Savings Master Summary. Retrieved from http://www.cityof[Removed].org/ 
pdf_forms/Disposal-Diversion-Revenue-Savings\%20_MasterSummary_CalendarYr09. pdf

Bureau of Solid Waste Management. City of [Removed]. (2010). Disposal/Diversion/ Revenue/Savings Master Summary. Retrieved from http://www.cityof[Removed]. org/pdf_forms/Disposal-Diversion-Revenue-Savings\%20_MasterSummary_CalendarYr2010.pdf

Casper, J., Pfahl, M., \& McCullough, B.P. (2014). Engaging fans in intercollegiate sustainability efforts: Understanding the environmental perspectives and actions of sport fans. Journal of Issues in Intercollegiate Athletics, 7(1), 65-91.

Casper, J., Pfahl, M., \& McSherry, M. (2012). Athletics department awareness and action regarding the environment: A study of NCAA athletics department sustainability practices. Journal of Sport Management, 26, 11-29.

Cialdini, R.B. (1993). Influence: Science and practice. New York, NY: HarperCollins College Publishers.

Cohen, J. (1988). Statistical Power Analysis for the Behavioral Sciences (2nd ed.). Hillsdale, NJ: Lawrence Erlbaum Associates.

Collins, A., Jones, C., \& Munday, M. (2009). Assessing the environmental impacts of mega sporting events: two options? Tourism Management, 30(6), 828-837. doi:10.1016/j. tourman.2008.12.006

Darnton, A. (2008). Practical guide: An overview of behavior change models and their uses. London: Government Social Research Unit.

Delmas, M.A., \& Burbano, V.C. (2011). The drivers of greenwashing. California Management Review, 54(1), 64-87. doi:10.1525/cmr.2011.54.1.64

De Young, R. (1989a). Recycling as appropriate behavior: A review of survey data from selected recycling education programs in Michigan. Resources, Conservation and Recycling, 3(4), 253-266. doi:10.1016/0921-3449(90)90022-V

De Young, R. (1989b). Exploring the difference between recyclers and non-recyclers: The role of information. Journal of Environmental Systems, 18, 341-351. doi:10.2190/ FBQC-5V5D-HHVC-V6X8

Drumwright, M.E. (1996). Company advertising with a social dimension: The role of noneconomic criteria. Journal of Marketing, 60, 71-87. doi:10.2307/1251902

Elkington, J. (1998). Cannibals with forks: The triple bottom line of 21st century business. Stony Creek, CT: New Society Publishers.

Emrich, E. (2014). Greening Big Ten athletics: Purdue University, taking the hard road. GreenSportsBlog. Retrieved from http://greensportsblog.com/2014/09/23/greeningbig-ten-athletics-purdue-university-taking-the-hard-road

Galbraith, S. \& McNabb, D. (1999, April). The environment and marketing education. Proceedings of Western Marketing Educators' Association, 112-115.

Gardner, G.T., \& Stern, P.C. (1996). Environmental Problems and Human Behavior. Boston, MA: Allyn and Bacon.

Geller, E.S. (1981). Evaluating energy conservation programs: Is verbal report enough? The Journal of Consumer Research, 8, 331-335. doi:10.1086/208872

Geller, E.S., Erickson, J.B., \& Buttram, B.A. (1983). Attempts to promote residential water conservation with educational, behavioral and engineering strategies. Population and Environment Behavioral and Social Issues, 6(2), 96-112. doi:10.1007/BF01362290

Govender, S., Munien, S., Pretorious, L., \& Foggin, T. (2012). Visitors' perceptions of environmental impacts of the 2010 FIFA World Cup: Comparisons between Cape Town and Durban. African Journal for Physical, Health Education. Recreation \& Dance, 2(2), 104-112.

Hart, S., \& Milstein, M. (2003). Creating sustainable value. The Academy of Management Executive, 17(2), 56-69. doi:10.5465/AME.2003.10025194

Hillman, A., \& Keim, G. (2001). Shareholder value, stakeholder management, and social issues: What's the bottom line? Strategic Management Journal, 22, 125-139. doi:10.1002/1097-0266(200101)22:2<125::AID-SMJ150>3.0.CO;2-H 
Hines, J.M., Hungerford, H.R., \& Tomera, A.N. (1986). Analysis and synthesis of research on responsible environmental behavior: a meta-analysis. The Journal of Environmental Education, 18, 1-8. doi:10.1080/00958964.1987.9943482

Hopper, J.R., \& Nielsen, J.M. (1991). Recycling as altruistic behavior: Normative and behavioral strategies to expand participation in a community recycling program. Environment and Behavior, 23(2), 195-220. doi:10.1177/0013916591232004

Hums, M. (2010). The conscience and commerce of sport management: one teacher's perspective. Journal of Sport Management, 24(1), 1-9.

Hums, M., Barr, C., \& Gullion, L. (1999). The ethical issues confronting managers in the sport industry. Journal of Business Ethics, 20, 51-66. doi:10.1023/A:1005951720456

Inoue, Y., \& Kent, A. (2012). Sport teams as promoters of pro-environmental behavior: An empirical study. Journal of Sport Management, 26, 417-432.

Johnston, C.E. (2006). Developing sustainable behaviors through community-based social marketing. Examining the Confluence of Environmental and Water Concerns: Proceedings of the World Environmental and Water Resources Congress 2006 (pp. 21-25). Reston: American Society of Civil Engineers.

Jordan, J.R., Hungerford, H.R., \& Tomera, A.N. (1986). Effects of two residential environmental workshops on high school students. The Journal of Environmental Education, 18(1), 15-22. doi:10.1080/00958964.1986.9942726

Kaufman, P., \& Wolff, E.A. (2010). Playing and protesting: Sport as a vehicle for social change. Journal of Sport and Social Issues, 34, 154-175. doi:10.1177/0193723509360218

Kellison, T.B., \& Kim, Y.K. (2012). Marketing Pro-Environmental Venues in Professional Sport: Planting Seeds of Change Among Existing and Prospective Consumers. Journal of Sport Management, 28, 162-175. doi:10.1123/jsm.2012-0210

Kollmuss, A., \& Agyeman, J. (2002). Mind the gap: Why do people act environmentally and what are the barriers to pro-environmental behavior? Environmental Education Research, 8, 239-260. doi:10.1080/13504620220145401

Kotler, P., \& Zaltman, G. (1971). Social marketing: An approach to planned social change. Journal of Marketing, 25, 3-12. PubMed doi:10.2307/1249783

Kotler, P., Roberto, N., \& Lee, N. (2002). Social Marketing: Improving the Quality of Life. Thousand Oaks, CA: Sage Publications.

Lefabvre, R.C., \& Flora, J.A. (1988). Social marketing and public health intervention. Health Education Quarterly, 15, 300-301. PubMed

Ludwig, T.D., Gray, T.W., \& Rowell, A. (1998). Increasing recycling in academic buildings: A systematic replication. Journal of Applied Behavior Analysis, 31(4), 683-686. doi:10.1901/jaba.1998.31-683

Mallen, C., Adams, L., Stevens, J., \& Thompson, L. (2010). Environmental sustainability in sport facility management: A Delphi study. European Sport Management Quarterly, 10, 367-389. doi:10.1080/16184741003774521

Mallen, C., \& Chard, C. (2011). A framework for debating the future of environmental sustainability in the sport academy. Sport Management Review, 14, 424-433. doi:10.1016/j. smr.2010.12.002

McCullough, B.P. (2013). Identifying the influences on sport spectator recycling behaviours using the theory of planned behaviour. International Journal of Sport Management and Marketing, 14(1), 146-168. doi:10.1504/IJSMM.2013.060631

McCullough, B.P., \& Cunningham, G.B. (2010). A conceptual model to understand the impetus to engage in and the expected organizational outcomes of green initiatives. Quest, 62, 348-363. doi:10.1080/00336297.2010.10483654

McSherry, M. (2009). 2009 Collegiate athletic department sustainability survey report. Lexington, KY: Association for the Advancement of Sustainability in Higher Education., Retrieved from http://www.aashe.org/files/documents/resources/2009-CollegiateAthletic-Department-Sustainability-Survey.pdf. 
McKenzie-Mohr, D. (2000). Promoting sustainable behavior: An introduction to communitybased social marketing. The Journal of Social Issues, 56(3), 543-554. doi:10.1111/00224537.00183

McKenzie-Mohr, D., \& Smith, W. (1999). Fostering sustainable behavior: An introduction to community-based social marketing. Gabriola Island, BC: New Society Publishers.

Midden, C.J., Meter, J.E., Weenig, M.H., \& Zieverink, H.J. (1983). Using feedback, reinforcement and information to reduce energy consumption in households: A field- experiment. Journal of Economic Psychology, 3, 65-86. doi:10.1016/0167-4870(83)90058-2

National Collegiate Athletic Association. (2008, 19 March). NCAA Schools Big On Environmental Initiatives. Environmental Leader. Retrieved from http://www.environmentalleader.com/2008/03/19/ncaa-schools-big-on-environmental-initiatives

National Collegiate Athletic Association. (2013). Greener Game Day: The idea of environmental sustainability takes root among schools. Retrieved from http://www.ncaa.org/ about/resources/media-center/news/greener-gameday

Natural Resources Defense Council. (2012). Game changer: How the sports industry is saving the environment. Retrieved from http://www.nrdc.org/greenbusiness/guides/ sports/files/Game-Changer-report.pdf

Natural Resources Defense Council. (2013, August). Game changer: How the sports industry is saving the environment. Retrieved from http://www.nrdc.org/greenbusiness/guides/ sports/files/collegiate-game-changers-report.pdf

Osterhus, T.L. (1997). Pro-social consumer influence strategies: When and how do they work? Journal of Marketing, 61, 16-29. doi:10.2307/1252084

Pallak, M.S., Cook, D.A., \& Sullivan, J.J. (1980). Commitment and energy conservation. In L. Bickman (Ed.), Applied Social Psychology Annual (pp. 235-253). Beverly Hills, CA: Sage.

Pew Research Center. (2009, October 22). Fewer Americans see solid evidence of global warming. Retrieved from http://pewresearch.org/pubs/1386/cap-and-trade-globalwarming-opinion

Pfahl, M. (2010). Strategic issues associated with the development of internal sustainability teams in sport organizations: A framework for action and sustainable environmental performance. International Journal of Sport Management, Recreation, and Tourism, 6, 37-61. doi:10.5199/ijsmart-1791-874X-6c

Pfahl, M. (2011). Sport and the natural environment: A handbook for sport managers. Dubuque, IA: Kendall Hunt.

Pfahl, M., Casper, J., Trendafilova, S., McCullough, B. P., \& Nguyen, S. N. (2014). Crossing Boundaries: An Examination of Sustainability Department and Athletics Department Collaboration Regarding Environmental Issues. Communication \& Sport, 2167479513519253.

Research International. (2000). Massachusetts DEP Recycling Participation Study. (Report prepared for the Massachusetts Department of Environmental Protection). Boston, MA.

Ross, A. (2005). The UK approach to delivering sustainable development in government: a case study in joined-up working. Journal of Environmental Law, 17(1), 27-49. doi:10.1093/envlaw/eqi002

Schultz, P.W., Nolan, J.M., Cialdini, R.B., Goldstein, N.J., \& Griskevicius, V. (2007). The constructive, destructive, and reconstructive power of social norms. Psychological Science, 18, 429-434. PubMed doi:10.1111/j.1467-9280.2007.01917.x

Shrivastava, P., \& Scott, P. (1992). Corporate self-greenewal: Strategic responses to environmentalism. Business Strategy and the Environment, 3, 9-21. doi:10.1002/ bse. 3280010303

Smith, A.C.T., \& Westerbeek, H.M. (2007). Sport as a vehicle for deploying social responsibility. Journal of Corporate Citizenship, 25, 43-54. doi:10.9774/GLEAF.4700.2007. sp.00007 
Tedeschi, R.G., Cann, A., \& Siegfried, W.D. (1982). Participation in voluntary auto emissions inspection. The Journal of Social Psychology, 117, 309-310. doi:10.1080/0022 4545.1982.9713446

Thibault, L. (2009). Globalization of sport: An inconvenient truth. Journal of Sport Management, 23, 1-20.

Trendafilova, S., \& Waller, S. (2011). Assessing the ecological impact due to disc golf. International Journal of Sport Management, Recreation, and Tourism, 8, 35-64. doi:10.5199/ijsmart-1791-874X-8c

United Nations Environmental Programme. (n.d.). Impact of sport on the environment. Retrieved from http://www.unep.org/sport_env/impactSport_Env.aspx

United States Census Bureau. (2011) GCT-T1-R. Total Population Estimate: City of [Removed]. Retrieved from http://factfinder.census.gov/servlet/GCTTable?ds_name=PEP_2009_EST\&-mt_name=PEP_2009_EST_GCTT1R_ST9S\&-geo_ id $=04000$ US47\&-format $=$ ST-9\&-tree_id $=809 \&$-context $=$ gct

Walker, M.B., \& Kent, A. (2009). Do fans care? Assessing the influence of corporate social responsibility on consumer attitudes in the sport industry. Journal of Sport Management, 23, 743-769.

Wang, T.H., \& Katzev, R.D. (1990). Group commitment and resource conservation: Two field experiments on promoting recycling. Journal of Applied Social Psychology, 20, 265-275. doi:10.1111/j.1559-1816.1990.tb00411.x

Wienreich, N. (1999). Hands-on Social Marketing. Thousand Oaks, CA: Sage Publications.

Winnett, R.A., Hatcher, J.W., Fort, T.R., Leckliter, I.N., Love, S.Q., Riley, A.W., . ... (1982). The effects of videotape modeling and daily feedback on residential electricity conservation, home temperature and humidity, perceived comfort, and clothing worn: Winter and summer. Journal of Applied Behavior Analysis, 15, 381-402. PubMed doi:10.1901/jaba.1982.15-381

Winnett, R.A., Leckliter, I.N., Chinn, D.E., Stahl, B., \& Love, S.Q. (1985). Effects of television modeling on residential energy conservation. Journal of Applied Behavior Analysis, 18, 33-44. PubMed doi:10.1901/jaba.1985.18-33

Zeigler, E.F. (2007). Sport management must show social concern as it develops tenable theory. Journal of Sport Management, 21(3), 297-318.

\section{Appendix}

\section{Personal Intercept Roles}

Starter: initial ice breaking; explaining the purpose of the research; gaining trust and introducing other tailgaters in group with other recycling educators

Middle Reliever:segment large groups into smaller/manageable sized groups; discuss photos from setting illustrating poor/lack of recycling on site; use provocative statistics printed on t-shirts about recycling waste and educate about importance and their role on site; request individual commitment to recycle while tailgating Closer: Summarize; ask for group commitment to recycle while tailgating; extend thanks and appreciation

Statistician/Reserve: Counting tailgaters; serve in backup role in case of attrition Scout: Observe and take notes; upon completion of intervention, interview 20\% of respondents in group 